\title{
Mercimek (Lens culinaris M.) Germplasmında Herbisit Toleransı için Genetik Çeşitliliğin Belirlenmesi
}

\author{
*Abdulkadir AYDOĞAN \\ Ayşegül GÜRBÜZ Kadir AKAN \\ Halil İbrahim Fırat KON \\ Zafer MERT Gözde Çelik ÖZER \\ Tarla Bitkileri Merkez Araştırma Enstitüsü, Ankara \\ *Sorumlu yazar e-posta (Corresponding author; e-mail): akadir602000@yahoo.com
}

\begin{abstract}
Öz
Mercimeğin verimini ve üretimini sınırlayan en önemli faktörlerden biri yabancı otlardır. Birçok yıl yabancı otlar mercimek veriminde \%100'e varan kayıplara neden olmaktadır. Özellikle İç Anadolu Bölgesinde kışlık üretimin önündeki en önemli engel yabancı otlardır. Son yıllarda dünyada Imidazolinone (IMI) grubu herbisitlere dayanıklı mercimekler geliştirilmiş ve çiftçinin kullanımına sunulmuştur. Çalışmanın amacı, Tarla Bitkileri Merkez Araştırma Enstitüsünde (TARM) geliştirilen mercimek hatlarının IMI grubu herbisitlere karşı dayanımının çeşitliliğini belirlemektir. Deneme 2014 yılı sera, 2014/15 yılında ise tarla koşullarında 2 yıl süre ile yürütülmüştür. Denemede Tarla Bitkileri Merkez Araştırma Enstitüsü Baklagil Islah Biriminde bulunan 759 adet hat materyal olarak kullanılmıştır. 2014 yılında serada yetiştirilen genotiplere erken gelişme döneminde etken maddesi $40 \mathrm{~g} / \mathrm{L}$ olan imazomax SL olan kimyasal kullanılmıştır. Yapılan gözlem ve değerlendirmeler sonucu 36 kışlık materyal seçilmiştir. Seçilen kışlık materyal 2014/2015 yetiştirme döneminde bölünmüş parsel deneme deseninde 3 tekrarlamalı olarak kontrol, normal ve 3 katı doz olacak şekilde Haymana'da tarlaya ekilmiştir. Çalışma sonucunda 35 numaralı kışık kırmızı mercimek genotipinin IMI grubu herbisite tolerant olduğu belirlenmiştir.
\end{abstract}

Anahtar Kelimeler: Imidazolinone (IMI), herbisit, mercimek, tolerant, yabancı ot

\section{Determination of Genetic Diversity for HerbicideTolerance in Lentil (Lens culinaris M.) Germplasm}

\begin{abstract}
Weed is one of the most important factors limiting yield and production of lentil. Many years, weed causes yield losses up to $100 \%$. Especially in Central Anatolia Region, weed is the most important constraint of the winter crop lentil production. In the World, lentil was developed to the diversity of resistant tolmidazolinone (IMI) group herbicide and presented to farmer for use recently. The aim of this study is to determine the resistance to IMI group herbicides of developed lentil lines by Central Research Institute for Field Crops (CRIFC). Experiments were conducted for two years; first year (2014) in green house condition and second year ( 2014/15 cropping season) in field condition respectively. In experiment 759 lines were tested. In 2014, Herbicide with active agent $40 \mathrm{~g} / \mathrm{LT}$ imazomax SL was sprayed on lentil genotypes of grown in green house. As a result of evaluation and observation, 36 winter type red lentil lines were selected. Selected winter red lines were planted in 2014/2015 cropping season with split plot experimental design and three replication. Standart doze and three times of normal doze herbicide were used in addition to control in Haymana. As a result of this study No. 35 line were identified as tolerant to herbicide.
\end{abstract}

Keywords: Imidazolinone (IMI), herbicide, lentil, tolerance, weed

\section{Giriş}

ürkiye de kırmızı ve yeşil olmak üzere iki tip mercimek yetiştirilmektedir. Yeşil mercimek yazlık olarak İç Anadolu ve Geçit Bölgelerinde, kırmızı mercimek ise daha çok kışlık olarak Güneydoğu Anadolu Bölgesinde ekilmektedir.
Ulkemizde 2014 yılı verilerine göre 233 bin hektar kırmızı mercimek ekim alanından 325 bin ton, 17 bin hektar yeşil mercimek ekim alanından ise 20 bin ton ürün alınmıştır. Kışlık ekilen kırmızı mercimeğin verimi 1400 kg/ha, 
yazlık ekilen yeşil mercimeğin verimi ise 1170 kg/ha'dır (TÜlK 2014). Türkiye, Kanada ve Hindistan'nın ardından Mercimek ekim alanı ve üretim açısından 3. sırada yer almasına rağmen, verim açısından 9. sırada yer almaktadır (FAOSTAT 2013).

Ülkemiz mercimek alanlarında verimliliği sınırlayan en önemli abiotik faktörler kuraklık, düşük ve yüksek sıcaklıklar, bitki besin maddeleri yetersizliği, tuzluluk ve yüksek kireç içeriğidir. Biotik faktörlerin başında ise yabancıot sorunu gelmektedir. Yabancıot, özellikle İç Anadolu Bölgesinde mercimeğin kışlık ekimini sınırlayan en önemli biotik strestir (Aydoğan 2009).

Mercimek bitkisinin aynı alanda bulunan yabancıotlar ile olan rekabeti oldukça azdır. Özellikle erken dönemde yabancıota karşı hassasiyeti daha da fazladır. Yabancıotlar ile rekabetinin düşük olmasının nedeni; bitki boyunun kısa ve erken dönemde büyüme oranının düşük olmasından kaynaklanmaktadır (Basler 1981). Mercimek erken dönemde yavaş gelişirken yabancıotlar ilk gelişim devresinde çok hızlı bir şekilde gelişerek kültür bitkisini bastırabilmekte ve gelişimini sınırlandırmaktadırlar.

Yabancıotlar bitki besin maddesi, su ve gelişim alanı olarak da kültür bitkisi ile bir rekabet içerisine girerek verim kaybına yol açmaktadırlar. Yabancıotun çeşidi ve yoğunluğuna bağlı olarak verim kayıpları da değişebilmektedir (Bukun and Guler 2005). Halila (1995), yabancı otların genellikle $\% 60$ oranında verim kaybına yol açtıklarını ve yüksek yoğunluklarda ise verim kaybının $\% 100$ 'lere varabileceğini vurgulamaktadır. Yabancıotlar mercimekte öncelikle verim kayıplarına yol açmakla birlikte zararlı ve hastalıklara konukçuluk yaparak da mercimeğe dolaylı olarak da zarar vermektedir. Mercimeğin hasat ve kalitedeki kayıpları da yabancıot istilasından kaynaklanmaktadır.

Yabancıotlar ile mücadelede kabul edilen beş farklı yöntem bulunmaktadır. Bunlar koruyucu (tohum ve ekici makine temizliği vs.), kültürel, mekanik, herbisit ve biyolojik mücadele yöntemleridir. Mercimekte yabancıotlar ile olan mücadele için bu yöntemlerden bazen teki bazen de birkaçı birlikte uygulanmaktadır (Yenish et al. 2009). Yabancıotlar ile mücadelede ekim öncesi ve/veya ekim sonrası uygulanan herbisitler kullanılmaktadır. Ancak ülkemizde mercimek alanlarında sadece dar yapraklı yabancıotlara karşı mücadele yapılmakta, buna karşın yüksek rekabet gücüne sahip geniş yapraklı yabancıotlara karşı etkin bir mücadele yapılamamaktadır. Bununla birlikte dinitroaniline kimyasal grubu (etki makenizması; Microtubulüs oluşumunun engellenmesi, etkili maddesi; pendimethalin, trifluralingibi), triazinone kimyasal grubu (etki mekanizması, fotosentezde photosystem II inhibitörü olup, etkili maddesi; metribuzin gibi),acetanalides kimyasal grubu (etkili maddesi; metolachlor) (Bhan and Kukula 1987; Solh and Pala 1990) ve imidazolinone kimyasal grubu [etkili maddesi; imazethapyr, etki mekenizması; acetohydroxyacidsynthase (AHAS) sentezinin engellenmesi] (Lyon and Wilson 2005) gibi herbisitlerin geniş yapraklı yabancıotların kontrolünde kullanıldığı bildirilmiştir. Ancak etkin ve yaygın kullanımı bulunmamaktadır. Bununla birlikte yabancıotlar ile mücadelede yabancıotu doğrudan hedef alan herbisitin kullanımı değil herbisite toleranslı genotip geliştirme çalışmaları ön plana çıkmaktadır.

Üründe büyük kayıplara neden olan dar ve geniş yapraklı yabancı otu kontrol eden imidazolinone grubu herbisitler, düşük dozda dahi iyi bir yabancı ot kontrolü sağlamaları, memelilere düşük oranda toksik olmaları ve çevre açısından uygun kullanıma sahip olmalarından dolayı imidazolinone dayanıklı mercimek geliştirmesinde ideal herbisitler olmalarını sağlamaktadır (Tan ve ark. 2005). Illk olarak 1992 yılında imidazolinonetolerant mısır geliştirilip ticarete konu olana kadar dört farklı ürün grubunda daha ticari olarak satışa başlanmıştır (Tan ve ark. 2005). İmidazolinone grubu herbisitler, acetohydroxyacidsynthase (AHAS) ya da acetolactatesynthase (ALS) enzimlerinin sentezini engelleyerek yabancıotların kontrolünü sağlamaktadır (Tan ve ark. 2005). Bu nedenle imidazolinone'lar transgenik olmayan ve herbisitlere dayanıklı ürün geliştirilmesinde birçok ideal veya istenilen özelliklere sahip kimyasallardır (Tan ve ark. 2005). Mercimekte imidazolinone toleransı çalışmaları ilk olarak Kanada'nın Saskatchewatn eyaletinde özel bir kimyasal firması ile baklagil yetiştiricileri birliği birlikte çalışması sonucunda geliştirilmiştir (Chant et al. 2009).

Bu çalışmanın amacı; mercimekte çıkış sonrası uygulanabilecek dar ve/veya geniş yapraklı yabancıotu kontrol eden 
imidazolinone kimyasal grubu herbisitlere karşı toleranslı genotipi mevcut germplasm içinden tanımlamaktır.

\section{Materyal ve Yöntem}

Materyal olarak Tarla Bitkileri Merkez Araştırma Enstitüsü Baklagil Islah Birimi tarafında geliştirilmiş 759 durulmuş mercimek hattı kullanılmıştır. 759 hattın 459 adeti kırmızı, 300 adeti ise sarı kotiledonlu mercimekten oluşmuştur. Deneme iki yıl süre ile 2014 yılında sera koşullarında, 2015 yılında ise tarla koşullarında yürütülmüştür.

\section{Sera çalışmaları}

Uygulama için \%60 toprak, $\% 20$ perlit ve $\% 20$ kumdan oluşan bir yetiştirme ortamı hazırlamıştır. Hazırlanan yetiştirme ortamının verimlilik analiz değerleri Çizelge 1'de verilmiştir. Hazırlanan ortam 759 adet çalışma materyali sera koşullarında yetiştirilmesi için $10 \mathrm{~cm} \times 10 \mathrm{~cm}$ x $11 \mathrm{~cm}$ 'lik saksılara konulmuştur. Ekim 18 Mart 2014 tarihinde sera şartlarında gerçekleştirilmiştir. Çıkışı sağlanan materyalin bitki boyu yaklaşık $5 \mathrm{~cm}$ olduğu dönemde etkili maddesi ImazamaxSL olan herbisit kullanılmıştır. Herbisitin bitkiye uygulama dozu ticari ürünün etiketi üzerinde firmanın tarla koşulları için önerdiği $125 \mathrm{ml} / \mathrm{da}$ olacak şekilde ekimden 21 gün sonra 8 Nisan 2014 tarihinde kullanılmıştır. İlacın bitkiye yapışmasının sağlanması için yapıştırıcı etkisi olan bir ürün litreye bir damla olacak şekilde ortama eklenmiştir.

Araştırmaya konu olan genotiplerin bitki boyu herbisit uygulamasından önce ve uygulamadan 21 gün sonra herbisit zararı gözlemi ise uygulamadan 24 ve 41 gün sonra olmak üzere 2 kez alınmıştır. 2014 yılında yürütülen sera çalışmasında.759 genotipden 2 genotipde yeterli gelişme sağlanamadığı için değerlendirme dışı tutulmuş olup araştırma 757 genotip üzerinden değerlendirilmiştir.

Çizelge 1. Sera için hazırlanan yetiştirme ortamının verimlilik analizi

Table 1. Soil productivitiy analysis of growth medium prepared for greenhouse

\begin{tabular}{ll}
\hline & Özellik \\
\hline Suyla doymuşluk (\%) & \\
Toprak sınıfı & 45 \\
EC (dS/m) & $\mathrm{L}$ \\
Toplam tuz (\%) & 0.699 \\
Toprak pH & 0.02 \\
$\mathrm{Lime} \mathrm{( \% )}$ & 7.97 \\
$\mathrm{P}_{2} \mathrm{O}_{4}$ & 8.57 \\
$\mathrm{~K}_{2} \mathrm{O}$ & 2.49 \\
Organik madde (\%) & 50.13 \\
\hline
\end{tabular}

\section{Tarla çalışmaları}

Tarla denemesi için materyal olarak bir yıl önce sera değerlendirmelerinde ümitvar olarak görülüp seçilen 4 sarı, 32 kırmızı kotiledonlu olmak üzere toplam 36 genotip kullanılmıştır. Her bir genotip $0.30 \mathrm{~m}^{2}(1 \mathrm{~m} \times 1$ sıra $\times 0.30 \mathrm{~m})$ ebedındaki parsellere markörle açılmış çizilere elle ekilmiştir. Her bir sırada $25 \pm 1$ adet tohum kullanılmış olup deneme planı Çizelge 2 de verilmiştir. Deneme kışlık olarak bölünmüş parsel deneme deseninde ve 3 tekerrürlü olarak 10 Ekim 2014 tarihinde Tarla Bitkileri Merkez Araştırma Enstitüsünün Haymana (Ankara) Araştırma ve Uygulama Çiftliği arazisine ekilmiştir.

Araşıtırma materyali üzerinde herbisitin etkisini gözlenmesi amacıyla kontrol (Kimyasal uygulama yapılmamış olup sadece eşit miktarda su uygulaması yapılmıştır), tarla koşulları için önerilen doz (125 ml/da) ve bu dozun üç katı (375 ml/da) olacak şekilde etkili maddesi ImazamaxSL olan herbisit ekimden 169 gün sonra 24 Nisan 2015 tarihinde kullanılmıştır.

İkinci yıl kimyasal uygulamasından (24.04.2015) önce ve sonra olmak üzere (17.06.2015) iki kez bitki boyu ile herbisit zararı ve $\% 50$ çiçeklenmeye kadar geçen gün sayısı gözlemleri alınmıştır. Sera ve tarla uygulamalarında bitkinin herbisite karşı gösterdiği reaksiyon Kuruma (K)-Hassas, S (Sararma/Yeşilimsi Sarı)-toleranslı, Y (Yeşil)dayanıklı olarak değerlendirilmiştir.

Çizelge 2. 2014/15 Haymana tarla deneme deseni Table 2. Experimental design for Haymana 2014/15

\begin{tabular}{lll}
\hline I. Tekerrür & II. Tekerrür & III. Tekerrür \\
\hline Kontrol & Üç katı Doz & Normal Doz \\
Normal Doz & Kontrol & Üç katı Doz \\
Üç katı Doz & Normal Doz & Kontrol \\
\hline
\end{tabular}

\section{Bulgular ve Tartışma}

\section{İlk yılın değerlendirmesi}

\section{Sera çalışmaları}

Sera şartlarında yürütülen çalışmalarda herbisit uygulamasından önce ve uygulandıktan 22 gün sonra bitki boyu ölçümü yapılmıştır. Uygulama öncesi yapılan ölçümlerde ortalama bitki boyu $6 \mathrm{~cm}$, uygulamasından sonra bu değer $6.5 \mathrm{~cm}$ olarak belirlenmiştir. İki ölçüm arasında geçen 24 günlük sürede herbisit bitki gelişimini etkilemiş ve kontrolle karşılaştırıldığında bitki de beklenen büyüme gerçekleşmemiş ortalama $0.5 \mathrm{~cm}$ uzama görülmüştür. Uygulama öncesi yapılan 
Çizelge 3. Sera çalışmaları sonucu elde edilen bitki boyu ve kimyasala olan reaksiyon gözlemleri Table 3. Surveys of plant heights and plant reactions to applied chemicals in greenhouse conditions

\begin{tabular}{cccc|ccc}
\hline $\begin{array}{c}\text { Gözlem } \\
\text { Tarihi }\end{array}$ & \multicolumn{3}{c|}{$\begin{array}{c}\text { Bitki Boyu cm } \\
\text { Ortalama }\end{array}$} & $\begin{array}{c}\text { Gözlem düşük } \\
\text { Tarihi }\end{array}$ & $\begin{array}{c}\text { Kn Yüksek } \\
\text { Hassas }\end{array}$ & $\begin{array}{c}\text { matalan olan reaksiyon ve } \\
\text { Dayanılsıl + Tolerant }\end{array}$ \\
\hline 08.04 .2014 & 6 & 2 & 13 & 02.05 .2014 & 701 & 56 \\
02.05 .2014 & 6.5 & 2 & 16 & 19.05 .2014 & 721 & 36 \\
\hline
\end{tabular}
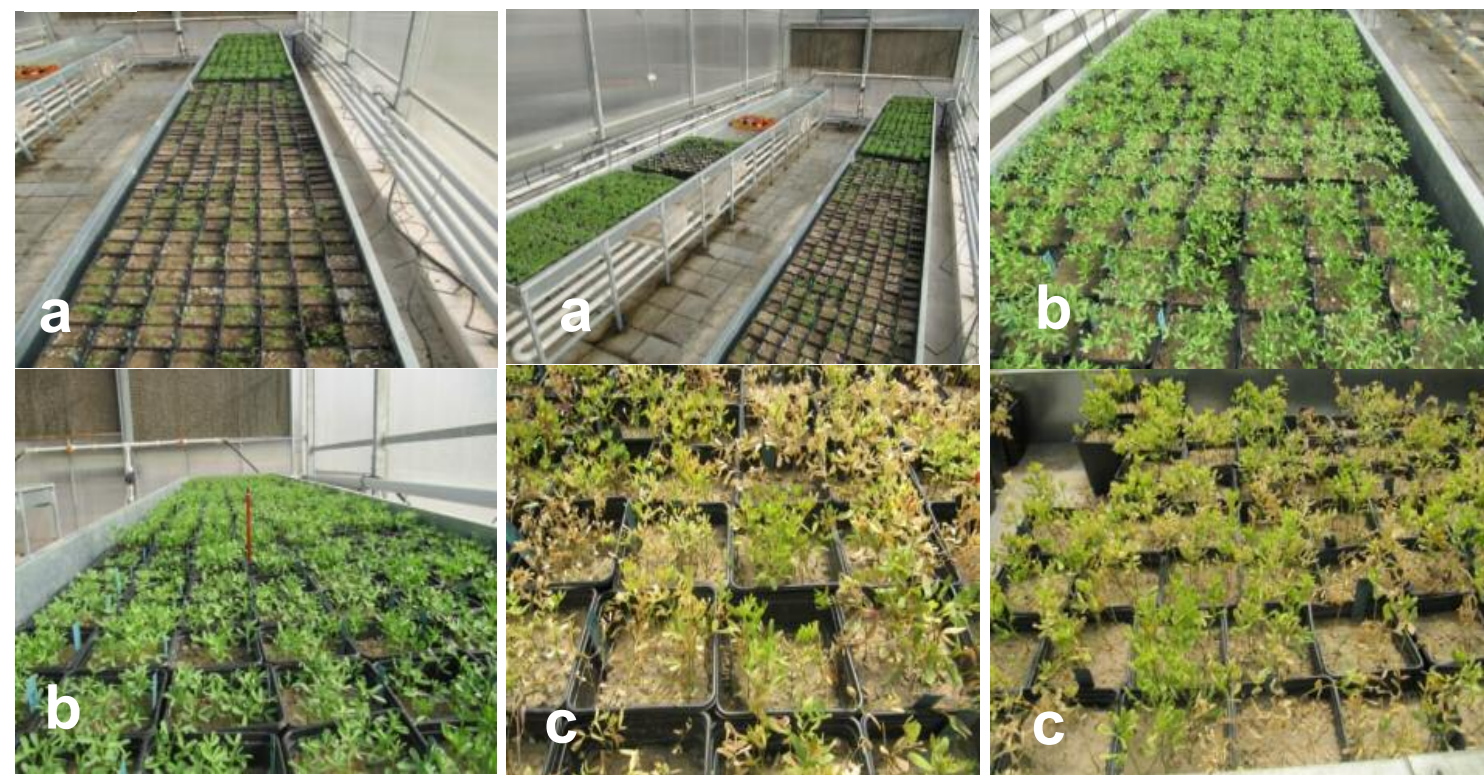

Şekil 1. Sera evresinde araştırma materyalinin herbisite olan reaksiyonları. a) Ekim ve çimlenme b) Herbisit uygulamadan öncesi c) Herbisit uygulamadan sonrası

Figure 1. Experiment materials reaction to herbicide a) Sowing and germination b) Before herbicide application c) after herbicide application

ölçümlerde en kısa bitki boyu $2 \mathrm{~cm}$ olarak belirlenmiştir. Bu durum uygulama sonrası herbisitin etkisi ile büyüme durmuş ve en düşük bitki boyu aynı kalmıştır. Diğer taftan bazı genotiplerde ise uygulama sonrası yaklaşık 3 cm'lik bir uzama belirlenmiştir.

$\mathrm{Bu}$ durum kimyasal uygulamadan sonra tolerant ve dayanıklı genotiplerinherbisite hassas olanlarla karşılaştırılamayacak seviye de olsa büyümeye devam ettiğini göstermiştir (Çizelge 3).Çalışma materyali uygulamadan 24 gün sonra herbisiteolan reaksiyonu açısından değerlendirildiğinde 701 genotip kuruma nedeniyle hassas, 56 genotip dayanıklı veya toleranslı, 41 gün sonra ise 721 genotip kuruma nedeniyle hassas, 36 genotip dayanıklı veya toleranslıolarak değerlendirilmiştir. Bu gözlemden hareketle bazı genotiplerin herbisite karşı gösterdikleri reaksiyonların farklı zamanlarda gerçekleştiği, bu durumun genotiplere göre etkilenmenin bazen yavaş bazen de hızlı olabileceği ve tamamen genotpin yapısına bağlı olduğu yorumu yapılabilir. Seçimi yapılan 36 genotipin 4 tanesi sarı, 32 tanesi kırmızı kotiledonlu olup kışlık yetiştiriciliğe uygundur.

\section{İkinci yılın değerlendirmesi}

\section{Tarla çalışmaları}

2014 yılında kurulan sera denemesinden herbisite toleranslı olarak değerlendirilerek seçilen 36 hat 2014-2015 güz döneminde tarla koşullarında denemeye alınmıştır. Kimyasal kullanılmadan önce deneme alanında yabancıot sayımı yapılmıştır. Sayım sonucunda ortalama $\mathrm{m}^{2}$ de 3 dar, 39 geniş yapraklı yabancıot tespit edilmiştir. Denemeye giren hatların herbisit uygulaması öncesi ve sonrasına bitki boyu, \%50 çiçeklenmeye kadar geçen gün sayısı ve etkili maddeye olan reaksiyonlarına ait gözlemlenmiş olup değerlendirmeler Çizelge 4'de verilmiştir.

Herbisit kullanılmadan önce hatların ortalama boyu kontrolde $7.0 \mathrm{~cm}$, önerilen dozda $7.9 \mathrm{~cm}$ ve üç katı dozu uygulamasında ise 9.7 $\mathrm{cm}$ olarak ölçülmüştür. Herbisit uygulamasından 54 gün sonra ise ortalama bitki boyu kontrol hatlarda $19 \mathrm{~cm}$ daha fazla uzayarak $26 \mathrm{~cm}$ ye ulaşmıştır. Önerilen ve önerileninin üç katı doz parsellerinde bulunan hatların biri hariç kalanları herbisitten zarar görmüştür. 
Çizelge 4. 2014/15 yetiştirme döneminde Haymana'da tarla koşullarında kurulan denemeye ait bazı gözlemler Table 4. Surveys of some traits from field conditions in Haymana, 2014/15 cropping season

\begin{tabular}{|c|c|c|c|}
\hline \multicolumn{4}{|c|}{ Herbisit uygulaması öncesi bitki boyu $(\mathrm{cm})$} \\
\hline & Kontrol & Önerilen doz & Önerilenin dozun üç katı doz \\
\hline Ortalama & 7.0 & 7.9 & 9.7 \\
\hline En az & 5.0 & 3.0 & 5.0 \\
\hline En fazla & 12.0 & 13.0 & 14.0 \\
\hline 35 Nolu Hat & 10.0 & 11.0 & 12.0 \\
\hline \multicolumn{4}{|c|}{ Herbisit uygulaması sonrası bitki boyu $(\mathrm{cm})$} \\
\hline Ortalama & 26.0 & - & - \\
\hline En az & 15.0 & - & - \\
\hline En fazla & 40.0 & - & - \\
\hline 35 Nolu Hat & 37.5 & 36.0 & 3206 \\
\hline \multicolumn{4}{|c|}{$\% 50$ çiçeklenmeye kadar geçen gün sayısı (gün) } \\
\hline $\begin{array}{l}\text { Genotiplerin } \\
\text { ortalaması }\end{array}$ & 217 & - & - \\
\hline 35 nolu hat & 218 & 219 & 219 \\
\hline \multicolumn{4}{|c|}{ Herbisituygulamasına tolerans veya dayanıklı genotip } \\
\hline Hat sayısı & 36 & 1 Dayanıklı & 1 Dayanıklı \\
\hline
\end{tabular}

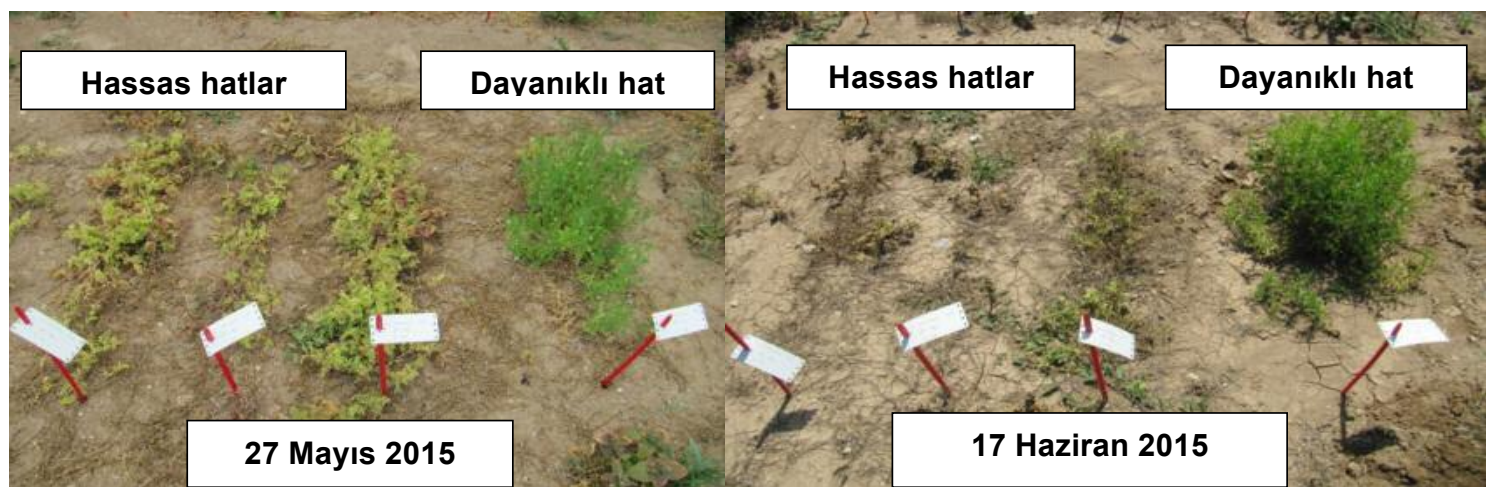

Şekil 2. Kimyasala dayanıklı ve hassas hatların uygulamadan sonra 2 farklı tarihteki (27 Mayıs ve 17 Haziran 2015) görünümleri

Figure 2. Views of resistant and susceptible lines after applying chemical at 2 different dates (27 May and 17 June 2015)

$\% 50$ çiçeklenmeye kadar geçen gün sayısı açısından genotipleri değerlendirdiğimizde kontrol parselinde bulunan hatların ortalaması 217 gün olmuş önerilen ve üç katı doz uygulanan parsellerde bulunan hatların biri hariç tamamı ölmüştür. Herbisit uygulamasına karşı dayanıklık gözleminde ise önerilen ve üç katı doz uygulamasında 35 numaralı hat dışında diğer hatların tamamı hassas bulunmuştur.

Çalışmada herbisit uygulamasından sonra genotiplerde alınan gözlemler neticesinde 35 numaralı hattın herbisitin iki uygulama dozuna karşı dayanıklı olduğu görülmüştür (Şekil 2). 35 numaralı hattın herbisit uygulamasından önce bitki boyu kontrol, önerilen ve üç katı doz uygulamalarında sırası ile $10 \mathrm{~cm}, 11 \mathrm{~cm}$ ve $12 \mathrm{~cm}$ olmuştur. Herbisit uygulamasından 54 gün sonra ise bu değerler $37.5 \mathrm{~cm}, 36 \mathrm{~cm}$ ve $32.6 \mathrm{~cm}$ olarak gerçekleşmiştir. Kimyasal uygulamasından 54 gün sonra 35 numaralı hat kontrolde $27.5 \mathrm{~cm}$, önerilen dozda $25 \mathrm{~cm}$ ve üç katı dozundaise $20.6 \mathrm{~cm}$ daha uzadığı ve herbisitten etkilenmediği anlaşılmıştır. \%50 çiçeklenmeye kadar geçen gün sayısında ise önerilen ve önerileninin üç katı dozda 35 numaralı hat hariç hiç birinde çiçeklenme görülmemiş ve bu değer her iki uygulamada 35 numaralı hat için 219 gün olmuştur.

\section{Sonuç}

Friesen and Wall (1986), trifluralin, ethalfluralin, triallate, metolachlorve metribuzinin gibi kimyasallar ile ekim öncesi ve $1.1 ; 1.1 ; 1.7$; 2.6 ve $0.28 \mathrm{~kg} / \mathrm{ha}$ dozlarla yapılan uygulamalarda mercimeğin tolerant olduğunu bildirmişlerdir. Ancak bu dozun 2.0 ve $3.0 \mathrm{~kg} / \mathrm{ha}$ çıkarıldığında mercimeğin de zarar gördüğünü ve hassaslaştığını bildirmişlerdir. Çalışmamızda imidazolinone toleransı belirlenen 35 numaralı 
mercimek hattındaönerilenin 3 katı dozda bile herhangi bir zarar görülmemiştir. Slinkard et al. (2007) belirttiği gibi sprey edilen alanlarda istenen vejetasyonda sadece imidazolin herbisitine dayanıklılık özelliğine sahip türlerin olmasına izin vermiş ve 35 numaralı hat gelişmiştir.

Hattın IMI grubu herbisitlere dayanıklılığına dair özelliğinin diğer farklı yeteneklere sahip mercimek çeşitlerine aktarılması ile ülke genelinde çiftçinin karlı bir üretim yapmasına imkan verecektir. Ayrıca mercimeğin diğer kültür bitkileri ile münavebeye girmesine kolaylaştıracağı gibi ekim alanı da yaygınlaşacaktır.

\section{Kaynaklar}

Aydoğan A., 2009. Mercimekte Kışa Dayanıklık Çalışmaları. Doktora Semineri, Ankara Üni. Fen Bilimleri Enstitüsü, Ankara

Basler F., 1981. Weeds and Their Control: Lentilcrop, (Ed: C. Webb, G.C. Hawtin), Lentils. Commonwealth Agricultural Bureau, Slough, UK, pp. 143-154

Bhan V.M. and Kukula S., 1987. Weeds and Their Control in Chickpea, (Ed: M.C. Saxena, K.B. Singh), The Chickpea. CAB International, Wallingford, Oxon,UK, pp. 319-328

Bukun B. and Güler B.H., 2005. Densities and importance values of weeds in lentil production. Int. J. Bot., 1: 15-18

Chant S., Bertholet J., Kuchuran M., Holmand R. and Vandenberg B., 2009. Development of imidazolinone tolerant lentil varieities www.ssca.ca/conference/conference2006/Ch ant.pdf (Erişim tarihi: 17.06.2015)
Halila M.H., 1995. Status and potential of wintersowing of lentil in Tunisia. Proceedings of the Workshop on Towards Improved Winter-Sown Lentil Production for the West Asia and North African High Lands, 1994, Antalya, Turkey, pp.172-183

FAOSTAT 2013. www.faostat.org (Erişim tarihi: 17.06.2015)

Friesen G.H. and Wall D.A., 1986. Tolerance of lentil (Lens culinaris Medik.) to herbicides. Canadian Journal of Plant Science, 66(1): 131-139

Lyon D.J. and Wilson R.G., 2005. Chemical weed control is dryland and irrigated chickpea. Weed Technology, 19: 959-965

Solh M.B. and Pala M., 1990. Weed control in chickpea. Options Mediterraneennes-Serie Seminaries 9, 93-99

Slinkard Al E., Vandenberg A. and Holm F.A., 2007. Lentil plants having increased resistance to imidazolinone herbicides. U.S. Patent No. 7.232.942. 19 Jun. 2007

Tan S., Evans R.R., Dahmer M.L., Singh B.K. and Shaner D.L., 2005. Imidazolinone-tolerant crops: History, current status and future. PestManag. Sci., 61: 246-257

TÜIK 2014. www.tarim.gov.tr, (Erişim tarihi: 17.06.2015)

Yenish J.P., Brand J., Pala M. and Haddad A., 2009. Weed Management, (Ed: W. Erskin, F.J. Muehlbauer, A. Sarkerand, B. Sharma), The Lentil, Botany, Production and Uses. CABI U.K 